\title{
A study to assess the occurrence and factors of maternal near-miss among women admitted in maternal unit in selected hospitals of Kolkata, India
}

\author{
Dipti Das*, Sujata Mitra, Saraswati Barui
}

Department of Obstetrics and Gynaecology, College of Nursing, R. G. Kar Medical College and Hospital, The West Bengal University of Health Sciences, Kolkata, West Bengal, India

Received: 27 August 2021

Accepted: 29 September 2021

\section{*Correspondence:}

Ms. Dipti Das,

E-mail: ddipti184@gmail.com

Copyright: ( $)$ the author(s), publisher and licensee Medip Academy. This is an open-access article distributed under the terms of the Creative Commons Attribution Non-Commercial License, which permits unrestricted non-commercial use, distribution, and reproduction in any medium, provided the original work is properly cited.

\begin{abstract}
Background: Assessment of the occurrence of maternal near-miss (an event in which a woman comes close to maternal death, but survive), identify the factors of maternal near-miss and to find out the association between determining factors and selected sample characteristics of maternal near-miss women.

Methods: A descriptive survey is carried out among purposively selected women admitted in the maternity unit of two tertiary hospitals of Kolkata. Data are collected by face-to-face interview using valid and reliable semi-structured interview schedule to identify factors of maternal near-miss. WHO selected maternal near-miss proforma (2011) is used for assessment of occurrence of maternal near-miss by using record analysis.

Results: The occurrence of maternal near-miss is identified as 100 out of 1669 women admitted in maternity unit. Eclampsia occurred maximum (27\%) followed by severe pre-eclampsia (19\%), severe PPH (6\%) among potentially life-threatening conditions. Multigravida (65\%), multipara (54\%), non-booked cases (5\%), duration of labour more than 18 hours (65\%), caesarean section (78\%), referred cases (79\%), maternal type 1 delay (53\%) and type 2 delay (67\%) all are the factors mainly responsible for developing maternal near-miss. Significant association present between reproductive and obstetrical factors and maternal education, marital age $(\mathrm{p}<0.01)$. Significant association is also present between maternal delay factors and residence, maternal education, monthly family income, marital age $(\mathrm{p}<0.01)$.

Conclusions: Exploring the factors of maternal near-miss may help to identify the factors early, which in turn will prevent the condition. Lesson can be learned from cases of near-miss which can serve as a useful tool in reducing maternal mortality ratio.
\end{abstract}

Keywords: Maternal near-miss, Occurrence, Maternal mortality, Maternity unit, Maternal delay

\section{INTRODUCTION}

Pregnancy is an amazing journey in a woman's life, and she spends each and every moment in pleasurable expectations. Although, it is a time of great contentment and achievement of life, pregnancy causes a lot of physiological and psychological changes. Beyond this normal predicted changes, sometimes there is sudden and unexpected complications may arise during pregnancy, childbirth and just after delivery. On this continuity, a pregnancy can be considered as being uncomplicated, complicated, severely complicated or life threatening. Nearly 5 women die every hour from complications related to childbirth in India which gives yearly death of 45,000 mothers as per report of World Health Organization (WHO). It accounts for $17 \%$ of such death globally. ${ }^{1}$ 
Survival of a pregnant woman depends on the severity of disease, her basic health, the health care facilities and the health workers of the health care system. According to WHO definition, 'A Maternal Near-Miss case is defined as a woman who nearly died but survived a complication that occurred during pregnancy, child-birth or within 42 days of termination of pregnancy'. Maternal Mortality Ratio (MMR) of India in the year 2016-2018 is $113 / 100000$ live births. It is declined by 17 points from 130/ 100000 live births in 2014-2016 as per report published by National Sample Registration System (SRS) survey data. ${ }^{2}$ Besides some direct causes of maternal death like obstetric haemorrhage, pre-eclampsia, eclampsia, sepsis; there are some other contributing factors like age at childbirth, gravida, parity, educational status of the women, preexisting disease conditions, economic status, transportation facility also play a major role.

According to the 2001-2003 (SRS) survey, the major causes of maternal mortality in India are $38 \%$ hemorrhage, $11 \%$ sepsis, $5 \%$ hypertensive disorder, $8 \%$ history of abortion and 5\% died due to some obstruction in the delivery process. There are also $34 \%$ cases whose causes could not be classified. ${ }^{3}$ The target of Sustainable Development Goal 3.1 (SDG) is to reduce the global maternal mortality ratio to less than 70 per 100,000 live births by $2030.4^{4}$ Inspite of therapeutic advancement, severe maternal morbidity and mortality continue to happen in obstetric patients in India. WHO and their partners started the Maternal Near-Miss Cases review (NMCR) approach to identify the causes of mortality and morbidity since $2004 .^{5}$ The objective of the NMCR is to identify the areas for improving quality of care and implementing solutions to the problems.

Maternal near-miss is more common than maternal deaths. Near-miss gives the proof about functioning of the health system, standard of care delivered to the obstetric mother, quick obstetric response by the health care team and the referral system. Evaluation of these system are usually felt easy by the researcher than mortality audit as in near-miss the woman is alive. ${ }^{6}$ Face-to-face interview is very important to know about the history of the pregnant women in the pregnancy period. Thus, the researcher also interested to investigate about the study as because the findings of this study help to identify the lacking areas which has to be improved for achieving the goal of reduction of maternal mortality rate of the country. Many research groups have already studied on the maternal near miss. For example: Tallapureddy et al conducted a retrospective study on maternal near-miss obstetric events where hemorrhage $(43.7 \%)$ was the leading cause of morbidity in near-miss cases and severe pre-eclampsia (50.54\%) was the most common complication among women with life threatening conditions was noted. ${ }^{7}$

Another study conducted by Bansal et al- out of 3539 deliveries, 39 near-miss cases were found. Hemorrhage was the major cause $(43.5 \%)$ of maternal near-miss followed by severe anaemia $(15.38 \%)$, rupture uterus
(15.38\%), pre-eclampsia / eclampsia (12.82\%), sepsis $(5.12 \%)$, complicated malaria $(5.12 \%)$ and hepatitis $(2.56 \%)$ were recorded. ${ }^{8}$

Most common direct complications of pregnancy were hemorrhage (26\%), eclampsia (18.7\%), sepsis (9.8\%), ruptured uterus (4\%) and obstructed labour (3.2\%) as per study of Kaur et al. ${ }^{9}$ The indirect causes were recorded as anaemia $(34.1 \%)$, respiratory disease $(4 \%)$, liver disease $(5.7 \%)$ and heart disease $(1.6 \%)$.

Although, these studies observed the direct and indirect causes of maternal near-miss, but there are some other sources for developing poor maternal outcome always remain hidden. In our study we have also observed the occurrence of different direct and indirect disease conditions of maternal near-miss. Besides these, we have also found so many other contributing factors which are responsible indirectly for developing severe maternal morbidity and mortality. We have shown the association between sample characteristics and factors of maternal near-miss by calculating the $\chi 2$ value. It is very effective to co-relate the poor socio-economic background of mother and development of severe complication of pregnancy. For this reason, this study findings need to be focused to reduce the contributing factors of maternal near-miss by implementing proper solution. It will help us to achieve the goal of SDG 3.14

\section{Operational definition}

\section{Maternal near-miss}

A woman presenting with any of the complications in terms of potentially life threatening conditions, critical intervention or organic dysfunction as diagnosed by physician on woman's treatment chart and surviving from those conditions that occurred during pregnancy, childbirth or within 42 days of termination of pregnancy should be considered as a maternal near-miss.

\section{Occurrence}

Occurrence refers to the number of near-miss cases as operationally defined occurred in respect of total admission of women in maternity unit during the study period.

\section{Maternity unit}

Maternity unit refers to antenatal ward, postnatal ward and labour room.

\section{METHODS}

\section{Settings of the study}

The study is conducted in the Department of Obstetrics and Gynaecology, R. G. Kar Medical College and Hospital, Kolkata and N.R.S. Medical College and Hospital, 
Kolkata, West Bengal, India which are a tertiary care centres and serve as a referral centre for other Primary Health Centre and District hospitals of West Bengal.

\section{Sample criteria of the study}

\section{Inclusion criteria}

Women who are willing to participate in the study. Women who are arrived in the maternity unit with any of the following maternal near-miss events.

(WHO selected near-miss criteria 10) from any group or developed with any of the following maternal near-miss conditions during their stay in the maternity unit are included -

Severe complications / potentially life-threatening conditions - severe $\mathrm{PPH}$, severe pre-eclampsia, eclampsia, sepsis or severe systemic infection, ruptured uterus. Critical intervention or intensive care unit admission - use of blood products (includes any blood transfusion), laparotomy (includes hysterectomy, excludes cesarean section), admission to ICU/HDU/ITU. Organic dysfunction /life threatening conditions - severe tachypnea (respiratory rate $>40 \mathrm{bpm}$ ) or severe bradypnea (respiratory rate $<6 \mathrm{bpm}$ ), shock, requiring cardiopulmonary resuscitation, intubation and ventilation not related to anaesthesia, severe hypoxemia (O2 saturation $<90 \%$ for $\geq 60 \mathrm{~min}$ ), oliguria non-responsive to fluids or diuretics, dialysis for acute renal failure, severe acute thrombocytopenia ( $<50000$ platelets $/ \mathrm{ml})$, jaundice in the presence of pre-eclampsia, haemorrhage or infection leading to hysterectomy, women who are available with those criteria during the study period, women who understand Bengali and English only.

\section{Exclusion criteria}

Women who have developed those maternal near-miss conditions related to accidental or incidental causes are excluded from the study.

\section{Research design}

This is a descriptive survey carried out among purposively selected women admitted in maternity unit of two tertiary hospital of Kolkata from $10^{\text {th }}$ December 2018 to $29^{\text {th }}$ December 2018.

Maternal near-miss cases, as per WHO selected near-miss criteria, are identified from the patient registers, case notes and $\log$ books. ${ }^{6}$ Observation checklist of WHO selected maternal near-miss proforma (2011) is used for assessment of occurrence of maternal near-miss by using record analysis. ${ }^{10}$ Face to face interview is taken to collect data regarding selected sample characteristics and factors of maternal near-miss by using semi-structured interview schedule. Total one hundred (100) sample cases are recorded.

\section{Statistical analysis}

Data are entered into a computer database using microsoft excel spreadsheet and statistical analysis is performed. The data are analysed by using descriptive and inferential statistics according to the study objectives. Frequency and percentage distribution are used for selected sample characteristics, occurrence and factors of maternal nearmiss. Chi-square is used to find out association between factors and selected sample characteristics of maternal near-miss.

\section{RESULTS}

Out of 1669 women admitted in Maternity unit during the study period, 1644 women delivered at the hospitals, and the rest ( 25 women) are admitted as postpartum cases or remain as antepartum cases in the hospital.

Table 1: Frequency percentage distribution of sample in terms of selected sample characteristics $(n=100)$.

\begin{tabular}{|ll|}
\hline Sample characteristics & Frequency (percentage) \\
\hline Age (years) & \\
\hline $16-22$ & 42 \\
\hline $23-29$ & 38 \\
\hline$>29$ & 20 \\
\hline Residence & \\
\hline Rural & 53 \\
\hline Urban & 27 \\
\hline Semi-urban & 20 \\
\hline Education & \\
\hline Primary & 26 \\
\hline Secondary & 38 \\
\hline Higher secondary & 18 \\
\hline Graduation and above & 18 \\
\hline Service & 7 \\
\hline Business & 2 \\
\hline Homemaker & 91 \\
\hline Monthly family income & \\
\hline$\leq$ Rs. 5000 & 34 \\
\hline Rs. 5001-10000 & 40 \\
\hline Rs. 10001-15000 & 11 \\
\hline$>$ Rs. 15000 & 15 \\
\hline Marital age in years & \\
\hline 13-17 & 34 \\
\hline 18-22 & 51 \\
\hline$>$ 22 & 15 \\
\hline
\end{tabular}

A total of 1600 live births, maternal deaths 1 and 100 maternal near-miss cases (according to WHO criteria) are recorded. So, the occurrence of maternal near-miss is 100 in respect of total admission of 1669 women in maternity unit. This gives an overall MNM (Maternal Near Miss) ratio of $62.5 / 1000$ live births. MNM rate is calculated as $59.91 / 1000$ obstetric admissions. The ratio between maternal near-miss cases and maternal deaths (Maternal near-miss mortality ratio) is 100 . 
From Table 1 we can observe that the maximum number of women $(42 \%)$ are in the age group of 16-22 years and from rural areas $(53 \%)$ and educated up to secondary level $(38 \%)$.

Table 2: Frequency percentage distribution of sample for the occurrence of maternal near-miss $(n=100)$.

\begin{tabular}{|ll|}
\hline $\begin{array}{l}\text { Occurrence of maternal near-miss } \\
\text { Severe complications / potentially life-threatening } \\
\text { conditions }\end{array}$ & $\begin{array}{l}\text { Frequency } \\
\text { percentage) }\end{array}$ \\
\hline Severe PPH & 6 \\
\hline Severe Pre-eclampsia & 19 \\
\hline Eclampsia & 27 \\
\hline Sepsis or severe systemic infection & 3 \\
\hline Ruptured uterus & 1 \\
\hline None & 46 \\
\hline $\begin{array}{l}\text { Critical intervention/intensive care } \\
\text { unit admission }\end{array}$ & 20 \\
\hline $\begin{array}{l}\text { Use of blood products (includes any } \\
\text { blood transfusion) }\end{array}$ & 4 \\
\hline $\begin{array}{l}\text { Laparotomy (includes hysterectomy, } \\
\text { excludes caesarean section) }\end{array}$ & 54 \\
\hline Admission to ICU/HDU/ITU & 41 \\
\hline None* & 2 \\
\hline Organic dysfunction/life threatening conditions \\
\hline $\begin{array}{l}\text { Severe tachypnea or severe bradypnea } \\
\text { (respiratory rate <6 bpm) }\end{array}$ & 2 \\
\hline Shock & 1 \\
\hline $\begin{array}{l}\text { Requiring cardiopulmonary } \\
\text { resuscitation }\end{array}$ & 2 \\
\hline $\begin{array}{l}\text { Intubation and ventilation not related } \\
\text { to anesthesia }\end{array}$ & 1 \\
\hline $\begin{array}{l}\text { Severe hypoxemia (O2 saturation } \\
\text { <90\% for 60 min) }\end{array}$ & 2 \\
\hline $\begin{array}{l}\text { Oliguria non-responsive to fluids or } \\
\text { diuretics }\end{array}$ & 1 \\
\hline Dialysis for acute renal failure \\
\hline $\begin{array}{l}\text { Hemorrhage or infection leading to } \\
\text { hysterectomy }\end{array}$ \\
\hline None* \\
\hline
\end{tabular}

note: *multiple responses.

Maximum number of women are home maker (91\%) and poor, monthly family income $\leq$ Rs. 5000/ (34\%) are also found. So, poor socio-economic status plays a great role for development of severe maternal morbidity.

In Table 2, from the group severe complications/ potentially life-threatening conditions, we can observe that maximum occurrence $(27 \%)$ is eclampsia followed by severe pre-eclampsia (19\%), severe PPH (6\%), sepsis $(3 \%)$. From critical intervention or intensive care unit admission, more than half of the women (54\%) admitted to ICU/HDU/ITU, use of blood products (20\%), laparotomy $4 \%$ cases are found. From organic dysfunction, we observe the maximum occurrences are severe tachypnea or severe bradypnea (2\%), severe hypoxemia (2\%), Dialysis for acute renal failure (2\%) and hemorrhage or infection leading to hysterectomy $(2 \%)$.

Table 3: Frequency percentage distribution of sample according to maternal delay factors $(n=100)$.

\begin{tabular}{|c|c|}
\hline Maternal delay factor & Frequency (percentage) \\
\hline \multicolumn{2}{|c|}{ Reported time to decide to seek care (Type 1 delay) } \\
\hline$\leq 3$ hours & 47 \\
\hline$>3$ hours & 53 \\
\hline \multicolumn{2}{|c|}{ Lack of awareness about danger sign of pregnancy } \\
\hline Yes & 63 \\
\hline No & 37 \\
\hline \multicolumn{2}{|l|}{ Any financial problem } \\
\hline Yes & 61 \\
\hline No & 39 \\
\hline \multicolumn{2}{|c|}{ Fear of being maltreated in healthy facility } \\
\hline Yes & 3 \\
\hline No & 97 \\
\hline \multicolumn{2}{|c|}{ Lack of companion in going to health facility } \\
\hline Yes & 26 \\
\hline No & 74 \\
\hline \multicolumn{2}{|c|}{ Lack of available person to take care } \\
\hline Yes & 27 \\
\hline No & 73 \\
\hline \multicolumn{2}{|c|}{ Any belief in alternative care } \\
\hline Yes & 11 \\
\hline No & 89 \\
\hline \multicolumn{2}{|c|}{ Lack of participation in decision making } \\
\hline Yes & 71 \\
\hline No & 29 \\
\hline \multicolumn{2}{|c|}{$\begin{array}{l}\text { Reported time to reach the health facility (Type } 2 \\
\text { delay) }\end{array}$} \\
\hline$\leq 1$ hour & 33 \\
\hline$>1$ hour & 67 \\
\hline \multicolumn{2}{|l|}{ Distance from health facility } \\
\hline$\leq 10 \mathrm{~km}$ & 24 \\
\hline$>10 \mathrm{~km}$ & 76 \\
\hline \multicolumn{2}{|l|}{ Means of transport } \\
\hline Ambulance & 35 \\
\hline Public transport and others & 65 \\
\hline \multicolumn{2}{|c|}{ Difficulty for finding transportation } \\
\hline Yes & 45 \\
\hline No & 55 \\
\hline \multicolumn{2}{|c|}{ Lack of funds for transportation } \\
\hline Yes & 42 \\
\hline No & 58 \\
\hline \multicolumn{2}{|c|}{ Reported time to receive treatment (Type 3 delay) } \\
\hline$\leq 30$ minutes & 96 \\
\hline$>30$ minutes & 4 \\
\hline
\end{tabular}

Figure 1 depicts that age at first conception occurred maximum $(62 \%)$ in the age above 18 years, majority of the women $(65 \%)$ are multigravida and multipara (54\%). So, multiparity and multigravida is the contributing factors for occurrence of maternal near-miss. Majority of the women's $(95 \%)$ registration status are booked in the health 
centre. The duration of labour is above 18 hours for more than half of the women (65\%) and more than three fourth of the women $(79 \%)$ are referred cases from any primary or secondary health care centre. Mode of delivery as caesarean section is more than three fourth of the women
(78\%). Some pre-existing disease conditions like history of Gestational Diabetes Mellitus (GDM) 31\% and history of abortion (35\%) have also responsible for developing maternal near-miss.

Table 4: Association between reproductive and obstetrical factor score with maternal education and marital age $(\mathbf{n}=100)$.

\begin{tabular}{|c|c|c|c|c|}
\hline \multirow[t]{2}{*}{ Variables } & \multicolumn{2}{|c|}{$\begin{array}{l}\text { Reproductive and obstetrical } \\
\text { factors }\end{array}$} & \multirow[t]{2}{*}{$\chi^{2}$} & \multirow[t]{2}{*}{ Significance } \\
\hline & $<$ Median (11) & $\geq$ Median (11) & & \\
\hline \multicolumn{5}{|l|}{ Maternal education } \\
\hline Primary & 4 & 22 & & \\
\hline Secondary & 10 & 28 & $14.39 *$ & Significant \\
\hline Higher secondary & 12 & 6 & & \\
\hline Graduation and above & 8 & 10 & & \\
\hline \multicolumn{5}{|l|}{ Maternal age in years } \\
\hline $13-17$ & 4 & 30 & & \\
\hline $18-22$ & 22 & 29 & $11.85^{*}$ & Significant \\
\hline$>22$ & 8 & 7 & & \\
\hline
\end{tabular}

$* \mathrm{P}<0.01$

Table 5: Association between maternal delay factors score with residence, maternal education, monthly family income and marital age in years $(n=100)$.

\begin{tabular}{|c|c|c|c|c|}
\hline \multirow{2}{*}{ Variables } & \multicolumn{2}{|c|}{ Maternal delay factor } & \multirow{2}{*}{$\chi^{2}$} & \multirow{2}{*}{ Significance } \\
\hline & $<$ Median (6) & $\geq$ Median (6) & & \\
\hline \multicolumn{5}{|l|}{ Residence } \\
\hline Rural & 9 & 44 & & \\
\hline Urban & 18 & 9 & 21.78 & Significant \\
\hline Sem-urban & 11 & 9 & & \\
\hline \multicolumn{5}{|l|}{ Maternal education } \\
\hline Primary & 2 & 24 & & \\
\hline Secondary & 10 & 28 & $27.32 *$ & Significant \\
\hline Higher secondary & 12 & 6 & & \\
\hline Graduation and above & 14 & 4 & & \\
\hline \multicolumn{5}{|l|}{ Monthly family income } \\
\hline$\leq$ Rs. 5000 & 6 & 28 & & \\
\hline Rs. 5001-10000 & 15 & 25 & $21.05^{*}$ & Significant \\
\hline Rs. 10001-15000 & 4 & 7 & & \\
\hline >Rs. 15000 & 13 & 2 & & \\
\hline \multicolumn{5}{|l|}{ Marital age in years } \\
\hline $13-17$ & 4 & 30 & & \\
\hline $18-22$ & 21 & 30 & $25.20 *$ & Significant \\
\hline$>22$ & 13 & 2 & & \\
\hline
\end{tabular}

$* \mathrm{P}<0.01$

From Table 3, we can observe that more than half of the women $(53 \%)$ have taken time to decide to seek care i.e. type 1 delay was more than 3 hours. Majority of the women $(63 \%)$ have lack of awareness about danger sign of obstetric complications. Maximum of the women (67\%) have taken time to reach the health facility i.e. type 2 delay is more than 1 hour. We can also find that $76 \%$ of the women have their distance from health facility is more than $10 \mathrm{~km}$. Public transport and others as their means of transport are used by $65 \%$ of women. So, maternal delay also played a major role for developing severe complication of the mother due to late initiation of treatment.

Chi square $\left(\chi^{2}\right)$ is computed between reproductive and obstetrical factors of maternal near-miss and maternal education in table 4 . The $\chi 2$ value is 14.39 , which shows significant association at degree of freedom (df) 3 with 
level of significance $(\mathrm{P})$ is 0.01 . Thus, it can be inferred that there is a co-relation between maternal educational status and development of severe maternal mortality and morbidity. Similarly, marital age and development of maternal near miss is also correlated with df 2 and level of significance 0.01. In Table 5 there is a significant association between maternal delay factors and the residence of women $\left(\chi^{2}=21.78\right)$ at 0.01 level of significance with $\mathrm{df}=2$ for developing severe maternal outcome. Similarly, there is a significant association present between maternal delay factors and selected sample characteristics (maternal education, monthly family income and marital age) of the maternal near miss women with respective degree of freedom. So, we can infer that maternal delay factor is strongly associated with poor socio-economic background of the mother.

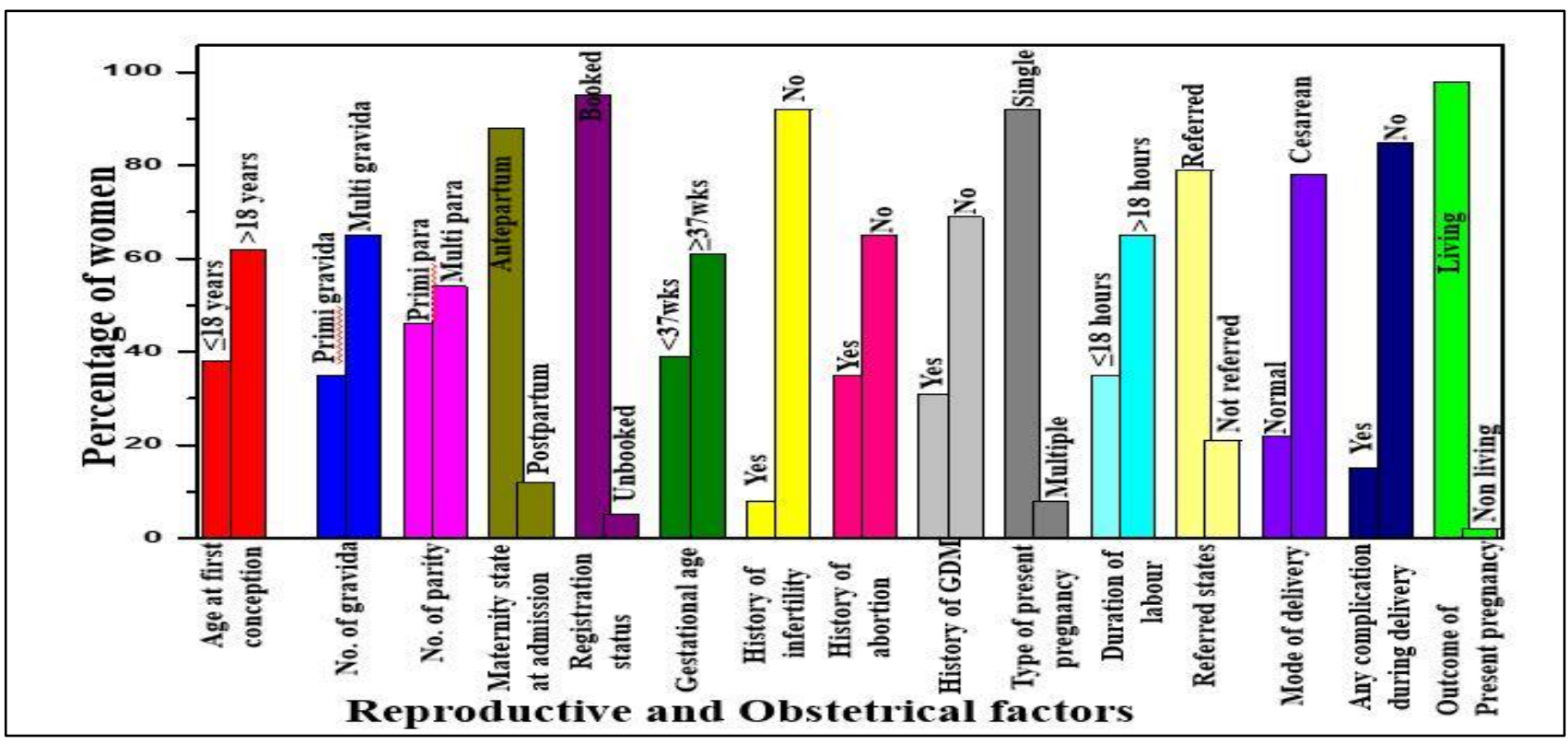

Figure 1: Percentage distribution of sample in terms of reproductive and obstetrical factors.

\section{DISCUSSION}

There are so many studies conducted on maternal nearmiss by several research groups. These studies give different findings which are very essential for improving the maternal outcome. In our present study, there are also some similar findings with the previous study findings but in some point of view it gives some new results which we have to look after for achieving our goal to reduce the maternal mortality and morbidity.

In our present study, a total number of 1600 live births, maternal deaths 1 and 100 maternal near-miss cases are recorded in respect of 1644 deliveries. Maximum occurrence of severe complications/ potentially lifethreatening conditions are eclampsia (27\%) followed by severe pre-eclampsia (19\%). This result is significantly different from the study of Panda et al on maternal nearmiss in Odisha. ${ }^{11}$ They found the number of near-miss cases 89 , total live births 1349 and maternal deaths 8 out of 1406 deliveries, where preeclampsia was the leading cause $(40.4 \%)$ followed by severe anaemia $(29.2 \%)$ and eclampsia $(19.1 \%)$. In case of our study, from the group critical intervention there are also other occurrences like intensive care unit admission (54\%), use of blood products (20\%), severe tachypnea or severe bradypnea (2\%),
Dialysis for acute renal failure (2\%), haemorrhage or infection leading to hysterectomy (2\%) crucially responsible for severe maternal morbidity. This result is comparable with the study of Iwuh et al where they found massive blood transmission $(38.5 \%)$, ventilation $(42.5 \%)$ and hysterectomy $(30.4 \%)$ are the causes of maternal near miss from the criteria critical intervention. ${ }^{12}$

In case of our study, the maternal near-miss mortality ratio is 100 and highest occurrence is eclampsia. Maternal Near Miss (MNM) ratio is 62.5/1000 live births and MNM rate is calculated as 59.91/1000 obstetric admissions. This result is different from the study of Das et al on maternal near-miss. ${ }^{13}$ They found 150 cases of near miss, 3123 live births and 9 cases of maternal deaths and maternal near miss mortality ratio is 16.66 , the highest mortality index was seen with cardiac causes $(25 \%)$ amid by sepsis $(16.6 \%)$ and eclampsia (14.2\%).

Many other factors like multigravida (65\%), multipara (54\%), term pregnancy $(61 \%)$, less monthly family income $(40 \%)$, obstructed labour $(65 \%)$ are also significantly responsible in developing maternal near-miss. Some preexisting diseases conditions (history of abortion (35\%), history of GDM $(31 \%)$ ), mode of delivery as cesarean section $(78 \%)$ and referred cases from other health centre (79\%) are accountable for the poor maternal outcome. The 
type 1 delay (53\%), lack of awareness about danger sign of pregnancy (63\%), type 2 delay $(67 \%)$, distance from health facility $(76 \%)$, lack of transportation facility $(65 \%)$ are the leading factors for poor prognosis of women. These findings are consistent with the cross-sectional study on near-miss obstetric events and its clinic-social corelates by Kumar et al in west Bengal, where higher age group $(88.5 \%)$, below poverty line status $(46.5 \%)$, term pregnancy (4/5 of total near-miss event), and higher gravida $(83.3 \%)$ and higher parity $(64.3 \%)$ significantly favoured the occurrence of Near-Miss obstetric events. ${ }^{14}$

There is a significant association present between maternal near-miss factors and residence, maternal education, monthly family income and marital age with level of significance $0.01(\mathrm{p}<0.01)$. This finding is also supported by Woldeyes et al studied in Jimma University teaching hospital, south west Ethiopia, where a significant correlation between maternal age, residential area, educational status and occupation with SMO $(p<0.0001)$ are found. ${ }^{15}$

\section{CONCLUSION}

We can conclude that the important causes of maternal near miss are eclampsia, severe pre- eclampsia, severe PPH and sepsis from our study of maternal near miss. These causes can be eliminated by taking proper care of antenatal mother by regular ANC visit, physical examination, blood pressure monitoring, some laboratory investigation and maintenance of aseptic technique during providing care to mother. Anemia should be prevented by iron and folic acid supplementation to the mother. Contributing factors for developing maternal near-miss can be avoided by creating awareness among common people about danger sign of pregnancy, improve the educational status of women, providing financial support to the under privileged section of the country, arranging proper referral system along with transportation facility, $100 \%$ institutional delivery by skilled healthcare workers, avoiding maternal delay, behavioural modification and immediate treatment in health care facility without delay must be emphasized. Plotting a partograph is very important when a women enter into active phase of labour to reduce the duration of labour from more than 18 hours. It helps to decide what action should be taken to save the life of mother and fetus. The face-to face interview from the participants are very important to understand what the obstacle they faced in the pregnancy time period. This will help to analyze the lacking areas in the obstetric care and provide the free lesson and opportunity to strengthen the quality of maternal health care service.

\section{ACKNOWLEDGEMENTS}

We thank Prof. Partha Bhowmik for suggestions and helping in data analysis. We also thank to K. P. Maity and Souryadipta Maity for reading the manuscript and some technical editing. We heartily thank to the women who participated actively and contributed to this study.
Funding: No funding sources

Conflict of interest: None declared

Ethical approval: The study was approved by the Institutional Ethics Committee

\section{REFERENCES}

1. 5 women in India die every hour during childbirth: WHO. Available at: https://indianexpress.com/article/ lifestyle/health/5-women-in-india-die-every-hourduring-childbirth-who-2856975/. Accessed on 20 July 2021.

2. Maternal health: UNICEF's concerted action to increase access to quality maternal health services. Available at: https://www.unicef.org/india/what-wedo/maternal-health. Accessed on 20 July 2021.

3. Park K. Park's textbook of Preventive and Social Medicine. 21st edition, Jabalpur: Banarsi das Bhanot. 2017;612-5.

4. Sustainable Development Goals (SDGs). Available at: https://www.who.int/health-topics/sustainabledevelopment-goals\#tab=tab_1. Accessed on 20 July 2021.

5. Conducting a maternal near-miss case review cycle at hospital level (2016) Available at: https://www.euro.who.int/_data/assets/pdf_file/000 3/324390/NMCR-manual-en.pdf. Accessed on 20 July 2021.

6. Tunçalp Ö, Hindin MJ, Souza JP, Chou D, Say L. The prevalence of maternal near miss: a systematic review. BJOG: An International Journal of Obstetrics \& Gynaecology. 2012;119(6):653-61.

7. Tallapureddy S, Velagaleti R, Palutla H, Satti CV. "Near-Miss" Obstetric events and maternal mortality in a Tertiary Care Hospital. Indian journal of public health. 2017;61(4):305-8.

8. Bansal M, Lagoo J. Study of near miss cases in Obstetrics and maternal mortality in Bastar, Chattisgarh, India. Int $\mathbf{J}$ Reprod Contracept Obstet Gynecol. 2016;5(3):620-3.

9. Kaur L, Mohi MK. A study of maternal near-miss cases in tertiary health centre in north India. Int $\mathbf{J}$ Reprod Contracept Obstet Gynecol. 2018;7:3239-43.

10. Evaluating the quality of care for severe pregnancy complications The WHO near-miss approach for maternal health. Available at: http://apps.who.int/iris/bitstream/handle/10665/4469 2/9789241502221_eng.pdf;jsessionid=EEBBAEAF7 1345A6036519D8798BAE6D5? sequence $=1$. Accessed on 20 July 2021.

11. Panda B, Panda SK. Maternal near-miss -An indicator of maternal health in a tertiary care hospital of Odisha. Journal of evolution of medical and dental sciences. 2018;7(12):1443-6.

12. Iwuh IA, Fawcus S, Schoeman L. Maternal near-miss audit in the Metro West maternity service, Cape Town, South Africa: A retrospective observational study. S Afr Med J. 2018;108(3):171-5.

13. Das A, Panda S, Singh S. Maternal near miss: a bigger challenge. Obstet Gynecol Int J. 2016;4(2):00099. 
14. Kumar R, Tewari A. "Near-Miss obstetric events" and its clinico-social correlates in a secondary referral unit of Burdwan District in West Bengal. Indian journal of public health. 2018;62(3):235.

15. Woldeyes WS, Asefa D, Muleta G. Incidence and determinants of severe maternal outcome in Jimma
University teaching hospital, south-West Ethiopia: a prospective cross-sectional study. BMC pregnancy and childbirth. 2018;18(1):1-2.

Cite this article as: Das D, Mitra S, Barui S. A study to assess the occurrence and factors of maternal nearmiss among women admitted in maternal unit in selected hospitals of Kolkata, India. Int J Reprod Contracept Obstet Gynecol 2021;10:4236-43. 